\title{
INFLUÊNCIA DA CALAGEM NO RENDIMENTO DE MATÉ RIA SECA DE PLANTAS DE COBERTURA E ADUBAÇÃO VERDE, EM CASA DE VEGETAÇÃO(1)
}

\author{
P. R. ERNANI (2) C. BAYER ${ }^{(3)} \&$ S. M. V. FONTOURA ${ }^{(4)}$
}

\begin{abstract}
RESUMO
A recuperação de solos degradados é lenta e onerosa. Plantas de cobertura de solo e adubação verde têm sido amplamente utilizadas nesse processo de recuperação, pois promovem alta produção de fitomassa com baixo custo, especial mente se forem tolerantes à acidez. 0 presente trabalho objetivou avaliar o efei to da calagem no rendi mento de matéria seca de dezesseis dessas espécies, em casa de vegetação. Oito espécies de inverno (Lollium multiflorum, Avena strigosa, Lathyrus sativus, Lupinus angusti fol ius, Pi sum sativum, Secalecereale, Vicia sativa e Vicia villosa) e oito de verão (Stizolobi um niveum, Stizolobium aterrinum, Stizolobi um deeringianum, Crotalaria juncea, Crotalaria retusa, Crotalaria spectabi lis, Cajanus cajan e Canavalia ensiformes) foram cultivadas em amostras da camada arável de dois solos ácidos catarinenses (Latossoso Bruno e Cambissolo Húmico), em Lages (SC), em 1997. Os tratamentos consistiram da aplicação de doses de calcário equivalentes a $0,0,25,0,50,1,00$ e 1,50 vezes a quantidade recomendada pelo método SMP para elevar o $\mathrm{pH}$ dos solos a 6,0. Os valores de Ca e Mg trocáveis aumentaram linearmente com a calagem e na mesma magnitude, ao redor de $3,0 \mathrm{mmol}_{\mathrm{c}} \mathrm{kg}^{-1}$ para cada incremento de 0,1 unidade de pH. O efeito da calagem no rendimento de matéria seca variou com o solo e, principalmente, com a espécie. Dez das 16 espécies não apresentaram aumento no rendimento de matéria seca com o aumento do $\mathrm{pH}$, em pelo menos um dos solos, e somente cinco espécies responderam à calagem de forma semelhante nos dois solos. $\mathbf{O}$ pH no qual as espécies tiveram a produção máxima de matéria seca foi igual ou inferior a 5,5 em qualquer dos solos e foi normalmente menor no Cambi ssolo do que no L atossolo, provavel mente pelo efeito benéfico da matéria orgânica em minimizar a toxidez do Al. Essas espécies podem, portanto, ser cultivadas com sucesso como melhoradoras das propriedades físicas, químicas e biológicas de solos ácidos degradados e requerem, para a produção máxima, menos calcário do que as doses atualmente recomendadas para a região.
\end{abstract}

Termos de indexação: acidez do solo, plantas de cobertura, calagem.

(1) Recebido para publicação em junho de 1999 e aprovado em maio de 2001.

(2) Professor do Departamento de Solos da Universidade do Estado de Santa Catarina - UDESC, Caixa Postal 281, CEP 88520-000 Lages (SC). Bolsista do CNPq. E-mail: prernani@cav.udesc.br

(3) Professor do Departamento de Solos da Universidade Federal do Rio Grande do Sul - UFRGS. Caixa Postal 776, CEP 90001-970 Porto Alegre (RS). Bolsista do CNPq.

(4) Pesquisadora da Fundação Agrária de Pesquisa Agropecuária - FAPA. Colônia Vitória - Entre Rios, CEP 85139-400 Guarapuava (PR). 


\title{
SUMMARY: LIMING INFLUENCE ON SHOOT DRY MATTER YIELD OF GREEN MANURE GREEN MANURE - COVER CROPS UNDER GREENHOUSE CONDITIONS
}

\begin{abstract}
Amelioration of degraded soils is time-consuming and expensive. Gren manure and cover crops have been widely used in this remediation process since these plants produce a large amount of phytomass at a low cost, especially if they are tolerant to soil acidity. This study was carried out to evaluate the effect of liming on dry matter yield of the following 16 species, under greenhouse conditions: eight winter crops (Lollium multiflorum, Avena strigosa, Lathyrus sativus, Lupinus angustifolius, Pisum sativum, Secal ecereale, Vicia sativa and Vicia villosa); and eight summer crops (Stizolobium niveum, Stizolobium aterrinum, Stizolobium deeringianum, Crotalaria juncea, Crotalaria retusa, Crotalaria spectabilis, Cajanus cajan and Canavalia ensiformes), grown in two acid south Brazilian soils (Haplumbrept and Hapludox), in Lages (SC), in 1997. Treatments consisted of dolomitic limestone rates equivalent to $0,0.25,0.50,1.00$ and 1.50 times the amount indicated by the SMP method to increase soil pH to 6.0. Exchangeable $\mathrm{Ca}$ and $\mathrm{Mg}$ increased linearly with liming, and at similar rates (about $3.0 \mathrm{mmol}_{\mathrm{c}} \mathrm{kg}^{-1} \mathrm{per} 0.1 \mathrm{pH}$ unit). The effect of liming on dry matter yield varied with soil and especially with plant species. Dry matter yield of ten species was not affected by liming in, at least, one soil, and only five species had similar response to liming on both soils. The soil pH for maximum yiedd was always equal to or bel ow 5.5, regardless of soil type Crop yield was higher and crop response to liming was normally lower on Haplumbrept than on Hapludox, probably due to the positive effect of soil organic matter, which was higher on Haplumbrept. These species may, thus, be successfully cultivated to improvethe physical, chemical and biological properties of degraded acid soils, requiring for maximum yield less limestonethan the present regional recommendation rates.
\end{abstract}

Index terms: green manure, cover crops, liming, soil acidity.

\section{INTRODUÇÃO}

O manejoinadequado, associado ao uso intensivo, degradou os solos agrícolas numa expressiva área da regiãoSul doBrasil (Wunscheet al., 1980; Wildner, 1990). Na maioria dessas lavouras, o solo apresenta $\mathrm{pH}-\mathrm{H}_{2} \mathrm{O}$ superior a 5,5 e adequada fertilidade química; noutras, no entanto, o pH ébaixo e os teores de alumínio trocável limitam o incremento no rendimento das culturas.

A recuperação desses sol os envolve al tos custos, muitas vezes indisponíveis, especialmente para pequenos produtores rurais. A introdução de plantas de cobertura de sol o eadubação verde, principalmente aquelas tolerantes à acidez, representa uma economia inicial nesse processo de recuperação, pois essa prática aumenta a adição de fitomassa (Lourenço et al., 1993), a fixação biológica de $\mathrm{N}$ e a reciclagem de nutrientes (Amado \& Wildner, 1995), tanto na camada arável como no subsol o. A utilização dessas plantas em lavouras ainda não degradadas, em sistemas de rotação ou sucessão de culturas, é uma prática essencial para conservar o solo e incrementar a produtividadedas culturas comerciais (DePolli \& Chada, 1989; Testa et al., 1992, Aita et al . 1994, Bayer \& Mielniczuk, 1997, Bayer et al., 1998).

Nos estados do Rio Grande do Sul e de Santa Catarina, recomenda-se el evar o $\mathrm{pH}-\mathrm{H}_{2} \mathrm{O}$ dos solos até 6,0 para a maioria das espécies vegetais cultivadas. Para atingir esse val or, nos sol os com alto tamponamento, énecessário aplicar mais de $10 \mathrm{t} \mathrm{ha-1}$ decal cário (Ernani \& Almeida, 1986; Almeida et al., 1999), o que representa um custo de investimento muito alto. A elevação do $\mathrm{pH}$ para 5,5, ao invés de 6,0 , representa uma opção para reduzir os custos iniciais com a calagem, pois os maiores benefícios para as plantas ocorrem quando o $\mathrm{pH}$ se eleva a 5,5 (Ernani et al., 1998). Para os solos altamente tamponados do estado de Santa Catarina, está sendo proposta uma elevação do $\mathrm{pH}$ ainda menor, para apenas 5,2. A elevação do pH até esseval or promoveu um aumento na saturação por bases de 24 para $50 \%$, uma diminuição no Al trocável de 42 para $7 \mathrm{mmol}_{\mathrm{c}} \mathrm{kg}^{-1} \mathrm{e}$, na saturação por Al, de $52 \%$ para apenas $8 \%$, com redução nas quantidades de cal cário de até 7,0 t ha-1 (Almeida et al., 1999).

A utilização deplantas tol erantes à acidez éoutra alternativa para diminuir os custos iniciais com a calagem. Algumas plantas de cobertura de solo e adubação verde podem ter incorporado tolerância genética à acidez por terem sido cultivadas por muitas décadas em solos ácidos, sem nenhum programa de melhoramento. Além da tolerância genética, a capacidade de adaptação dessas plantas a baixos valores de $\mathrm{pH}$ aumenta com o aumento dos teores de matéria orgânica e de P disponível no solo (Vidor \& Freire, 1972; Ernani et al., 2000). Nos solos degradados, os teores de matéria orgânica diminuíram ao longo do tempo, diferentemente dos de $\mathrm{P}$, que aumentaram, porque essas lavouras receberam grandes quantidades de fertilizantes no passado. 
Este estudo objetivou avaliar, em casa de vegetação, a influência da calagem na produção de matéria seca de dezesseis espécies de plantas de cobertura eadubação verde, cultivadas em amostras de dois sol os ácidos catarinenses.

\section{MATERIAL E MÉTODOS}

Foram realizados dois experimentos em casa de vegetação, respectivamente, no outono/inverno e na primavera/verão de 1997, no Centro de Ciências Agroveterinárias da Universidade do estado de Santa Catarina (UDESC), em Lages (SC). Utilizaramse amostras coletadas da camada de $0-20 \mathrm{~cm}$ de profundidade de dois solos da região do Planal to Sul Catarinense (Latossolo BrunoAlumínicoTípico, LB, e Cambissolo Húmico, $\mathrm{CH}$ ), coletadas no município de Lages. O LB tinha pH-água 4,25; P-Mehlich = $1,0 \mathrm{mg} \mathrm{kg}^{-1} ; \mathrm{K}=130 \mathrm{mg} \mathrm{kg}^{-1}$; matéria orgânica = $40 \mathrm{~g} \mathrm{~kg}^{-1}$; argila $=500 \mathrm{~g} \mathrm{~kg}^{-1} ; \mathrm{H}+\mathrm{Al}=77 \mathrm{mmol}_{\mathrm{c}} \mathrm{kg}^{-1}$; Ca, Mg e Al trocáveis = 16,6, 5,7 e 15,9 $\mathrm{mmol}_{\mathrm{c}} \mathrm{kg}^{-1}$ respectivamente; CTC efetiva $=4,15 \mathrm{cmol}_{\mathrm{C}} \mathrm{kg}^{-1}$, saturação por bases $(\mathrm{V})=23 \%$, esaturação por $\mathrm{Al}(\mathrm{m})$ $=38 \%$. O CH continha pH-água 4,20; P-Mehlich = $3,0 \mathrm{mg} \mathrm{kg}^{-1} ; \mathrm{K}=150 \mathrm{mg} \mathrm{kg}^{-1}$; matéria orgânica $=$ $60 \mathrm{~g} \mathrm{~kg}^{-1} ;$ argila $=400 \mathrm{~g} \mathrm{~kg}^{-1} ; \mathrm{H}+\mathrm{Al}=139 \mathrm{mmol}_{\mathrm{C}} \mathrm{kg}^{-1}$; Ca, Mg e Al trocáveis =13,2, 4,9 e 47,4 mmol ${ }_{\mathrm{C}} \mathrm{kg}^{-1}$, respectivamente; $C T C$ efetiva $=6,93 \mathrm{cmo}_{\mathrm{C}} \mathrm{kg}^{-1}$, saturação por bases $(\mathrm{V})=13 \%$, e saturação por $\mathrm{Al}(\mathrm{m})=68 \%$.

Em cada experimento, foram cultivadas oito espécies de plantas de cobertura e adubação verde, hibernais ou estivais, dependendo da época de cultivo. Os tratamentos consistiram da apl icação de quantidades de calcário dolomítico (PRNT 100\%), equivalentes a $0,0,25,0,50,1,00$ e 1,50 vezes a quantidade recomendada pelo método SMP para elevar o pH em água a 6,0 (respectivamente, 0, 2,5,

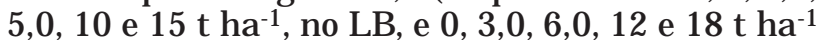
no $\mathrm{CH}$ ). No experimento de outono/inverno, realizado de abril a julho, foram cultivados azevém (Lollium multiflorum), aveia preta (Avena strigosa), xinxo (Lathyrus sativus), tremoço azul (Lupinus angustifolius), ervilha forrageira (Pisum sativum), centeio (Secale cereale), ervilhaca comum (Vicia sativa) e ervilhaca peluda (Vicia villosa). No experimento de primavera/verão, de setembro a dezembro, cultivaram-se mucuna anã (Stizolobium deeringianum), mucuna cinza (Stizol obium niveum), mucuna preta (Stizolobium aterrinum), feijão-deporco (Canaval ia ensiformes), guandu anão (Cajanus cajan), Crotalaria juncea, Crotalaria retusa e Crotalaria spectabilis. Utilizou-se o delineamento experimental completamente casualizado, com os tratamentos (sol os, espécies e doses de cal cário) distribuídos num esquema fatorial, com duas repetições.

As amostras de sol o foram passadas em peneira de $5 \mathrm{~mm}$ de abertura para remoção de fragmentos de raízes. As doses de calcário foram aplicadas manualmente, em unidades experimentais de $5,5 \mathrm{~kg}$ deterra (base seca), sendo esta, a seguir, umedecida a $80 \%$ da capacidade de retenção de água.

Quinze dias após, as unidades experimentais foram transferidas para baldes plásticos, com capacidade para oito litros, nas quais se aplicaram uréia (100 mg kg-1 de $\mathrm{N}$ ), superfosfato triplo (150 $\mathrm{mg} \mathrm{kg}^{-1}$ de P) e doreto de potássio (100 $\mathrm{mg} \mathrm{kg}^{-1}$ deK), realizando-sea semeadura em seguida. Quatro dias após a emergência das plântulas, efetuou-se o desbaste. Nas espécies de inverno, foram deixadas de 10 a 20 plantas/vaso, e nas de verão, de 4 a 10 plantas/vaso, dependendo da espécie. O tempo de cultivo foi de 60 dias para as espécies de inverno, mucunas e feijão-de-porco, e de 120 dias para as crotalárias. Durante o período de cultivo, realizouse o controle diário da umidade do sol o pela adição de água destilada, por meio da pesagem dos vasos.

No experimento com as espécies de verão, foram utilizadas as mesmas amostras de solo do experimento anterior, nas quais apenas se reaplicou uréia, na dose de $100 \mathrm{mg} \mathrm{kg}^{-1}$ de $\mathrm{N}$. Os demais nutrientes ( $\mathrm{P}$ e K $)$ não foram reaplicados porque os teores nas amostras encontravam-seacima do limite de suficiência utilizado para experimentos em vasos.

Além da produção de matéria seca da parteaérea das plantas, determinaram-se os valores de $\mathrm{pH}$ em água e os teores de cálcio, magnésio e alumínio trocáveis do solo. As amostras de sol o foram coletadas ao término do segundo experimento, após a homogeneização completa do solo contido em cada vaso. O pH foi determinado em água, na relação sol o/ água de 1:1, conforme método-padrão utilizado pela rede oficial de laboratórios dos estados do Rio Grande do Sul e Santa Catarina (CFSRS/SC, 1995). O Ca, o Mg e o Al trocáveis foram extraídos com solução de $\mathrm{KCl} 1,0$ mol L-1 edeterminados por espectrofotometria de emissão induzida por plasma (ICP). O H +Al foram extraídos com solução de acetato de cálcio $2 \mathrm{~mol} \mathrm{~L}^{-1}$, pH 7,0, e determinados por titulometria de neutralização com $\mathrm{NaOH}$.

O efeito da calagem foi avaliado por meio de análises de regressão. Avaliou-se a relação entre as doses de calcário e a produção de matéria seca da parte aérea das plantas de cobertura por meio da significância a $5 \%$ do coeficiente de determinação de regressões polinomiais de primeiro e segundo grau. Além disso, foram estimados o pH em água, a saturação por bases (V\%) ea fração da recomendacão do método SMP no qual as espécies apresentarama máxima produtividade.

\section{RESULTADOS E DISCUSSÃO}

A aplicação de quantidades crescentes de cal cário aumentou o pH ea saturação por bases e diminuiu o Al trocável (Quadro 1). Cada t ha-1 de calcário aplicada promoveu o aumento de 0,13 unidade de 
pH no LB (pH $=4,29+0,135$ t ha-1 $\left.^{-1} r^{2}=0,98\right)$ e de 0,10 unidade de $\mathrm{pH}$ no $\mathrm{CH}(\mathrm{pH}=4,25+0,095$ t ha-1; $\left.r^{2}=0,99\right)$.

$\mathrm{O}$ pH não atingiu os valores preestabel ecidos pelo método SMP, em nenhum sol o. N o tratamento onde se aplicou $100 \%$ da dose recomendada, o pH, que deveria atingir 6,0 , chegou até 5,8 , no Latossolo, e somente até 5,5, no Cambissolo. A percentagem de saturação por bases $(\% \mathrm{~V})$ aumentou com a el evação do $\mathrm{pH}-\mathrm{H}_{2} \mathrm{O}$ em maior magnitudeno LB (\%V =-445,1 + $\left.165,9 \mathrm{pH}-13,1 \mathrm{pH}^{2} ; \mathrm{r}^{2}=0,998\right)$ do que no $\mathrm{CH}$ $\left(\% \mathrm{~V}=-381,6+134,9 \mathrm{pH}-9,78 \mathrm{pH}^{2} ; \mathrm{r}^{2}=0,998\right)$. Essa diferença entre os solos deveu-se ao maior tamponamento do $\mathrm{CH}$, provavel mente, pel os maiores valores de matéria orgânica e de Al trocável apresentados por esse solo. O incremento nos teores de $\mathrm{Ca}$ e $\mathrm{Mg}$ foi linear, tanto no Latossolo [Ca $\left(\mathrm{mmol}_{\mathrm{c}} \mathrm{kg}^{-1}\right)=-74+22,0 \mathrm{pH}, \mathrm{r}^{2}=0,98 ; \mathrm{Mg}$ $\left.\left(\mathrm{mmol}_{\mathrm{c}} \mathrm{kg}^{-1}\right)=-110+28,1 \mathrm{pH}, \mathrm{r}^{2}=0,98\right]$ como no Cambissolo [Ca $\left(\mathrm{mmol}_{\mathrm{c}} \mathrm{kg}^{-1}\right)=-123+32,8 \mathrm{pH}$, $\mathrm{r}^{2}=0,98 ; \mathrm{Mg}\left(\mathrm{mmol}_{\mathrm{c}} \mathrm{kg}^{-1}\right)=-130+31,3 \mathrm{pH}$, $\left.r^{2}=0,97\right]$, e os dois nutrientes tiveram um aumento de aproximadamente $3,0 \mathrm{mmol}_{\mathrm{C}} \mathrm{kg}^{-1}$ para cada incremento de 0,1 no pH, à exceção do Ca no Latossolo, onde o incremento foi de 2,2 $\mathrm{mmol}_{\mathrm{C}} \mathrm{kg}^{-1}$.

Nas maiores doses de calcário, os teores de Mg trocável praticamenteseigualaram aos deCa, eisso tem ocorrido quando são usadas quantidades

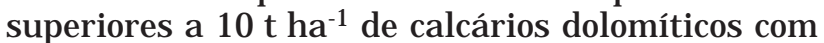
relação $\mathrm{Ca} / \mathrm{Mg}$ ligeiramente superior à unidade (Ernani et al., 1998; Ernani et al., 2000).

O efeito da calagem no rendimento de matéria seca da parteaérea variou com osol oe, principalmente, com a espécie vegetal (F iguras 1, 2, 3 e 4). A calagem não afetou a produção de matéria seca de seis espécies vegetais no Latossol o (aveia preta, ervilha forrageira, ervilhaca comum, tremoço azul, mucuna anã, e mucuna cinza) e de quatro espécies no Cambissolo (centeio, mucuna preta, feijão-de-porco, e Crotalaria spectabilis), porém nenhuma delas deixou de responder à aplicação de calcário simultaneamente nos dois solos (Quadro 2). Nove espécies tiveram o rendimento aumentado com a cal agem em apenas um dos solos, mas somente seis, das 16 espécies vegetais aval iadas, tiveram aumento de rendimento simultaneamente nos dois sol os. Para estas, a resposta foi quadrática em cinco (azevém, xinxo, Crotalaria juncea, Crotal aria retusa eguandu anão), e na ervilhaca peluda foi linear num solo e quadrática no outro. Em apenas duas espécies (centei o e ervilhaca peluda), eambas no L atossolo, o rendimento aumentou linearmente com a quantidade de cal cário aplicada (Figuras 1 e 2). O tremoço azul não respondeu à calagem no LB e seu rendimento decresceu com a aplicação de calcário no $\mathrm{CH}$ (Figura 2). Esses resultados mostram que a falta de resposta à calagem, quase sempre atribuída às características de planta, também está relacionada com propriedades de solo.

No Cambissolo, 11 espécies apresentaram um incremento quadrático na produção de matéria seca com a calagem: azevém, aveia preta, xinxo, ervilha forrageira, ervilhaca comum, ervilhaca peluda, mucuna anã, mucuna cinza, Crotalaria juncea, Crotalaria retusa e guandu anão (Figuras 1, 2, 3 e 4). Todas tiveram a máxima produtividade em valores de $\mathrm{pH}$ iguais ou inferiores a $5,5(\% \mathrm{~V}<64)$ e, em nove espécies, o $\mathrm{pH}$ ideal foi igual ou inferior a $5,2(\% \vee<55)$ (Quadro 2).

Quadro 1. Valores de pH em água, alumínio, cálcio e magnésio trocáveis, e percentagem de saturação por alumínio (m) e por bases (V) de dois solos ácidos do Planalto Sul Catarinense, considerando a aplicação de quantidades crescentes de calcário. Média das amostras das unidades experimentais de cada dose de calcário (16 espécies e duas repetições), coletadas após o cultivo do segundo experimento

\begin{tabular}{|c|c|c|c|c|c|c|c|}
\hline Calcário & F ração-SMP(1) & pH & Al & $\mathbf{m}$ & $\mathrm{Ca}$ & Mg & $\mathbf{v}$ \\
\hline t ha-1 & & & $\mathrm{mmol}_{\mathrm{c}} \mathrm{kg}^{-1}$ & $\%$ & \multicolumn{2}{|c|}{$-\mathrm{mmol}_{\mathrm{c}} \mathrm{kg}^{-1}$} & $\%$ \\
\hline \multicolumn{8}{|c|}{ Latossolo Bruno } \\
\hline 0 & 0 & 4,25 & 15,9 & 38 & 16,6 & 5,7 & 23 \\
\hline 2,5 & 0,25 & 4,60 & 7,1 & 13 & 26,8 & 17,7 & 40 \\
\hline 5,0 & 0,50 & 4,98 & 3,9 & 5 & 38,2 & 32,3 & 57 \\
\hline 10 & 1,00 & 5,84 & 0,0 & 0 & 56,5 & 52,5 & 75 \\
\hline 15 & 1,50 & 6,20 & 0,0 & 0 & 58,6 & 61,4 & 80 \\
\hline \multicolumn{8}{|c|}{ Cambissolo Húmico } \\
\hline 0 & 0 & 4,22 & 47,4 & 68 & 13,2 & 4,9 & 13 \\
\hline 3,0 & 0,25 & 4,50 & 26,8 & 38 & 24,7 & 15,4 & 28 \\
\hline 6,0 & 0,50 & 4,91 & 9,4 & 11 & 40,4 & 27,8 & 46 \\
\hline 12 & 1,00 & 5,46 & 0,0 & 0 & 60,4 & 50,9 & 62 \\
\hline 18 & 1,50 & 5,92 & 0,0 & 0 & 67,4 & 55,6 & 75 \\
\hline
\end{tabular}

(1) Fração da dose de calcário estimada pelo método SMP para elevar o pH em água a 6,0. 


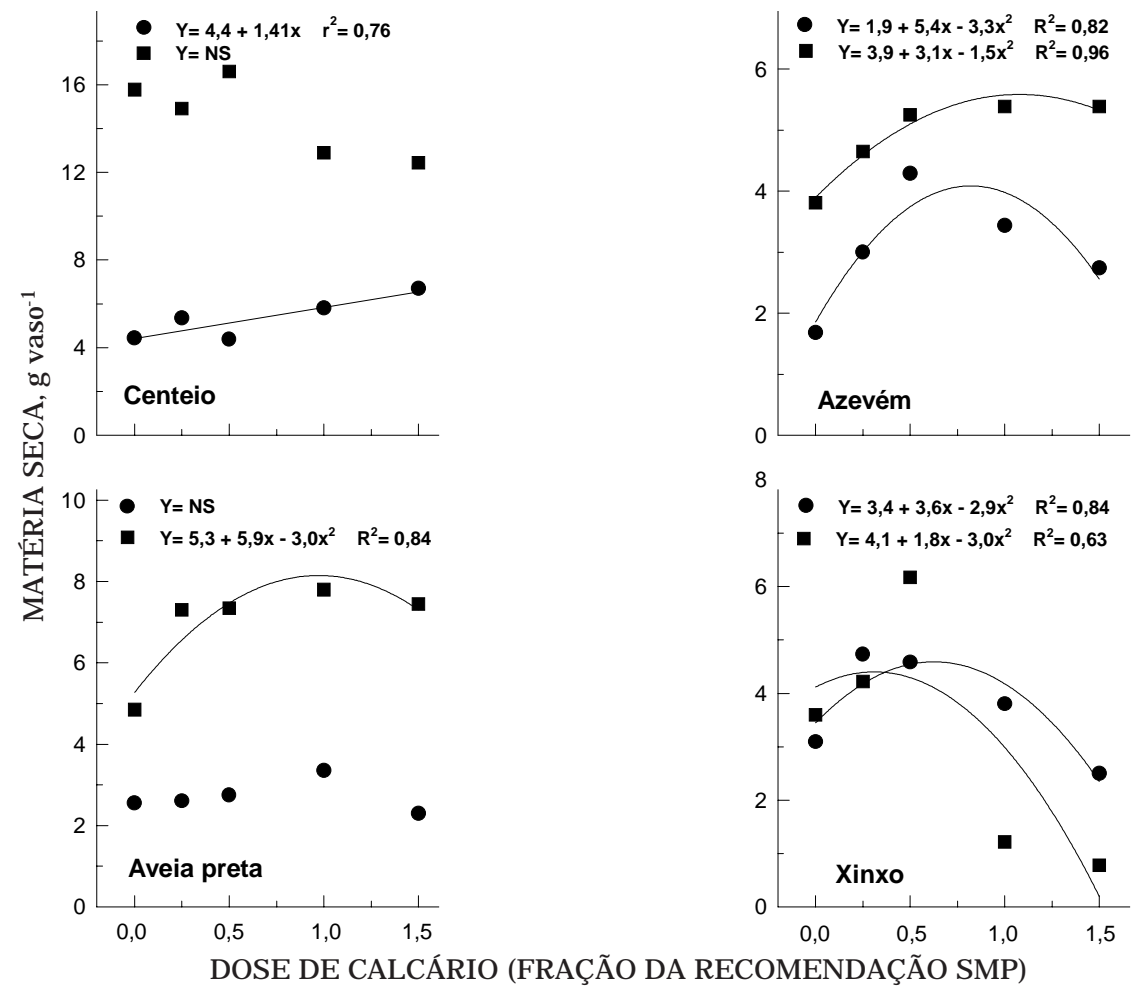

Figura 1. Rendimento de matéria seca de três espécies de gramíneas e do xinxo usadas para adubação verde e cobertura hi bernal do solo, considerando a dose de calcário expressa em fração da quantidade recomendada pelo método SMP para elevar o pH em água a 6,0, no Latossolo Bruno (0) e no Cambissolo Húmico ( $\square$ ).
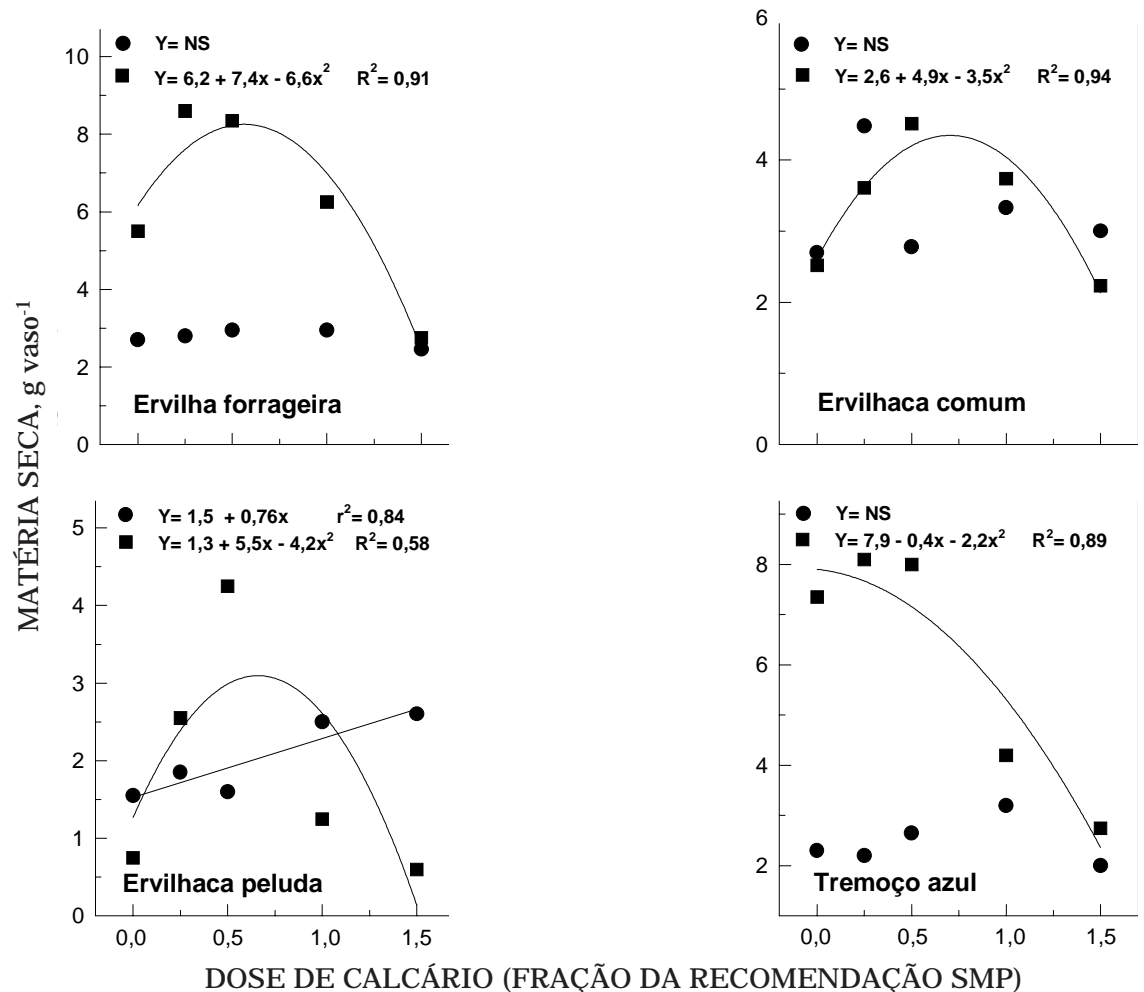

Figura 2. Rendi mento de matéria seca de quatro espécies de leguminosas usadas para adubação verde $e$ cobertura hibernal do solo, considerando a dose de calcário expressa em fração da quantidade recomendada pelo método SMP para elevar o pH em água a 6,0, no Latossolo Bruno (0) e no Cambissolo Húmico ( $\square$ ). 


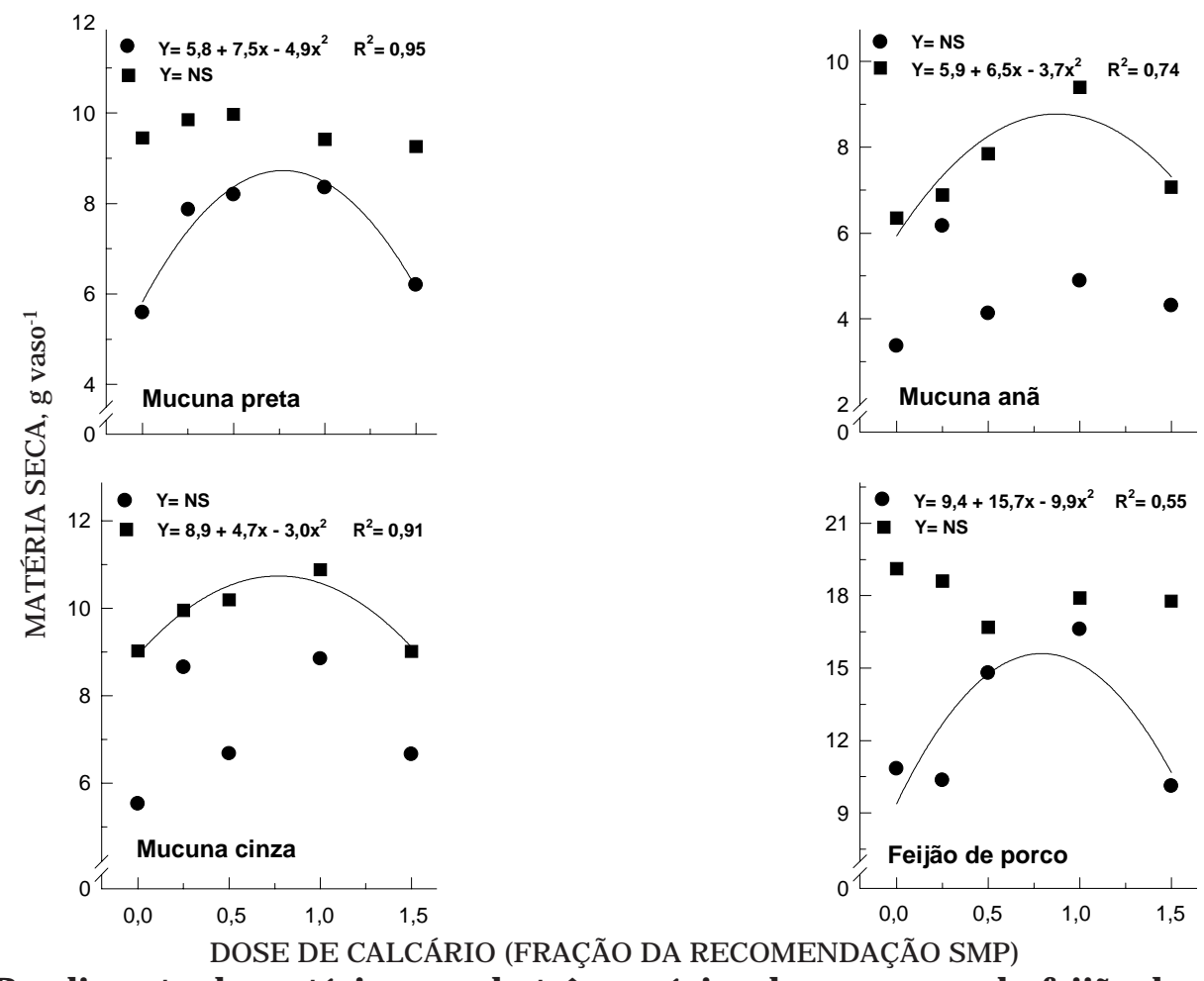

Figura 3. Rendimento de matéria seca de três espécies de mucuna e do feijão-de-porco usadas para adubação verde e cobertura estival do solo, considerando a dose de calcário expressa em fração da quantidade recomendada pelo método SMP para elevar o pH em água a 6,0, no Latossolo Bruno (๑) e no Cambissolo Húmico ( $\square$ ).

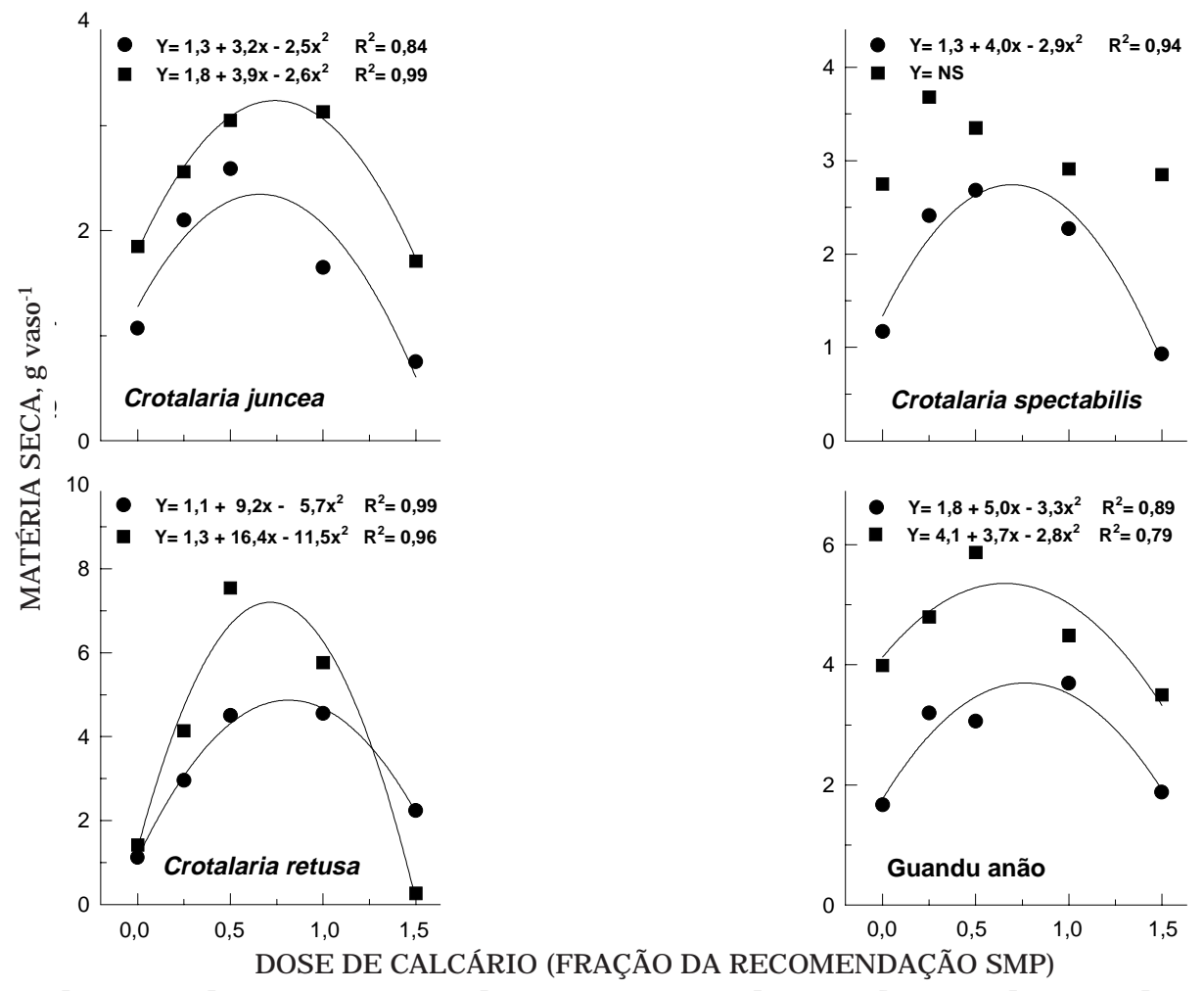

Figura 4. Rendimento de matéria seca de três espécies de crotalária e do guandu anão usadas para adubação verde e cobertura estival do solo, considerando a dose de calcário expressa em fração da quantidade recomendada pelo método SMP para elevar o pH em água a 6,0, no Latossolo Bruno (0) e no Cambissolo Húmico (ם). 
No Latossolo, oito espécies tiveram resposta quadrática à calagem: azevém, xinxo, mucuna preta, feijão-de-porco, Crotalaria juncea, Crotalaria spectabilis, Crotalaria retusa e guandu anão (Figuras 1, 2, 3 e 4). À semel hança do Cambissolo, todas tiveram rendimento máximo de massa seca em valores de $\mathrm{pH}$ inferior a 5,5 (\%V <69), porém somente duas em $\mathrm{pH}$ inferior a $5,2(\% \mathrm{~V}<60)$ (Quadro 2), mostrando que não há necessidade de el evar o pH do sol o até 6,0 para essas espécies. Como as doses de cal cário aplicadas foram subestimadas, as produções máximas de matéria seca seriam obti das com frações da recomendação do SMP ainda menores que as apresentadas no quadro 2.

Inexistência ou baixa resposta à calagem têm si do verificadas, para outras espécies vegetais, principalmente em solos com altos teores de argila e de matéria orgânica (Caires \& Rosolem, 1993; Ernani et al., 1998; Caires et al., 1998; Ernani et al., 2000), ou naqueles em que a disponibilidade de $\mathrm{P}$ no sol o é alta (Vidor \& Freire, 1972; Silva et al., 1994; Ernani et al., 2000). Por essa razão, Al meida et al. (1999) propuseram a elevação do $\mathrm{pH}$ dos solos altamente tamponados do estado de Santa Catarina para apenas 5,2.

Das cinco espécies que apresentaram resposta quadrática à calagem nos dois sol os (azevém, xinxo, Crotalaria juncea, Crotal aria retusa eguandu anão), em três delas o pH ideal foi menor no Cambissolo do que no L atossolo, eem apenas uma ocorreu o inverso (Quadro 2). De maneira geral, o pH e a \%V onde se obteve o máximo rendimento de matéria seca foram menores no $\mathrm{CH}$ do que no LB, graças provavel mente ao efeito benéfico da matéria orgânica em diminuir a atividade doAl (Hoyt \& Turner, 1975; Bloom et al., 1979).

Apesar de ter o mesmo $\mathrm{pH}$ em água $(4,2), 0$ Cambissolo apresentou maior quantidade de $\mathrm{Al}$ trocável $\left(47,4 \mathrm{mmol}_{\mathrm{C}} \mathrm{kg}^{-1}\right)$ e maior saturação por $\mathrm{Al}$ na CTC (68\%) queo Latossolo (15,9 mmol ${ }_{c} \mathrm{~kg}^{-1}$ e $38 \%$ respectivamente) (Quadro 1$)$, porém maiores teores de matéria orgânica (60 e $40 \mathrm{~g} \mathrm{~kg}^{-1}$ respectivamente). Além do efeito da matéria orgânica humificada, os resíduos orgânicos ainda não decompostos, tanto de animais (E rnani \& Gianello, 1983) como de vegetais (Myazawa et al., 1993), têm sido eficientes em diminuir oAl trocável do solo, o que representa um benefício adicional para o uso de espécies de cobertura de sol o e adubação ver de em solos ácidos. É possível que o efeito benéfico da matéria orgânica sobre o Al explique a razão de ser a resposta à calagem menor nos solos orgânicos do que nos minerais (Quaggio et al., 1985).

O rendimento das espécies também foi sempre maior no $\mathrm{CH}$ do que no LB, exceto para oxinxo, para o qual a produtividade foi semel hantenos dois solos (Figuras 1, 2, 3 e 4). Além do maior teor de matéria orgânica e da menor quantidade de argila, outros fatores podem ter contribuído para o maior potencial produtivo do Cambissolo relativamente ao do Latossolo.

Quadro 2. Valores de pH-água, saturação por bases (V) e fração da dose de calcário estimada pelo método SMP para elevar o pH em água a 6,0 de dois solos ácidos do Planalto Sul Catarinense, estimados pelas equações de regressão, nos quais as espécies de plantas de cobertura e adubação verde apresentaram a máxima produção de matéria seca

\begin{tabular}{|c|c|c|c|c|c|c|}
\hline \multirow{2}{*}{ Espécie $e^{(1)}$} & \multicolumn{3}{|c|}{ Latossolo Bruno } & \multicolumn{3}{|c|}{ Cambissolo Húmico } \\
\hline & pH & V (\%) & SMP & pH & V (\%) & SMP \\
\hline $\begin{array}{l}\text { Azevém } \\
\text { Centeio }\end{array}$ & $\begin{array}{l}5,3 \\
\text { (2) }\end{array}$ & 66 & 0,82 & $\begin{array}{l}5,5 \\
(1)\end{array}$ & 64 & 1,0 \\
\hline Ervilhaca comum & (1) & & & 5,1 & 52 & 0,70 \\
\hline Xinxo & 5,1 & 60 & 0,62 & 4,8 & 41 & 0,30 \\
\hline Aveia preta & (1) & & & 5,3 & 59 & 0,98 \\
\hline Ervilha forrageira & (1) & & & 4,9 & 44 & 0,56 \\
\hline Ervilhaca peluda & (2) & & & 5,0 & 48 & 0,65 \\
\hline Tremoço azul & (1) & & & (3) & & \\
\hline Mucuna anã & (1) & & & 5,2 & 55 & 0,88 \\
\hline Mucuna cinza & (1) & & & 5,2 & 55 & 0,78 \\
\hline Mucuna preta & 5,4 & 69 & 0,76 & (1) & & \\
\hline Feijão-de-porco & 5,3 & 66 & 0,79 & (1) & & \\
\hline Guandu anão & 5,4 & 69 & 0,76 & 5,1 & 52 & 0,66 \\
\hline Crotalaria juncea & 5,1 & 60 & 0,64 & 5,1 & 52 & 0,75 \\
\hline Crotalaria retusa & 5,4 & 69 & 0,81 & 5,0 & 48 & 0,71 \\
\hline Crotalaria spectabilis & 5,3 & 66 & 0,69 & (1) & & \\
\hline
\end{tabular}

$\overline{(1)}$ Não houve resposta à calagem. ${ }^{(2)} \mathrm{A}$ resposta foi linear. ${ }^{(3)} \mathrm{A}$ resposta foi negativa. 
O potencial de desenvolvimento destas espécies em condições de pH baixo e toxidez de Al pode ser aproveitado na recuper ação de áreas degradadas, as quais, em vez de serem deixadas em pousio, podem ser cultivadas com espécies recuperadoras. Outro benefício da tolerância à acidez pode estar na capacidade deexploração de camadas mais profundas em sol os com el evada acidez subsuperficial, de difícil correção pela calagem. Nestas condições, as plantas decobertura contri bui rão para aumentar a recidagem de nutrientes e incorporação de fitomassa.

\section{CONCLUSÕES}

1. O efeito da calagem na produção dematéria seca variou com o solo e, principalmente, com a espécie. Dez das 16 espécies não responderam à calagem num ou no outro solo, e em apenas cinco delas a resposta à calagem foi semel hante nos dois solos.

2. $\mathrm{OpH}$ que apresentou o máximo rendimento de matéria seca foi igual ou inferior a 5,5 nos dois solos, e normalmente, menor no Cambissolo do que no Latossolo.

\section{AGRADECIMENTOS}

Ao pesquisador Tássio Rech, da EPAGRI - Lages (SC), pel o fornecimento das sementes da mai oria das espécies utilizadas neste estudo.

\section{LITE RATURA CITADA}

AITA, C.; CERETTA, C.A.; THOMAS, A.L.; PAVINATO, A. \& BAYER, C. Espécies de inverno como fonte de nitrogênio para o milho no sistema de cultivo mínimo e feijão em plantio direto. R. Bras. Ci. Solo, 18:101-108, 1994.

ALMEIDA, J.A.; ERNANI, P.R. \& MAÇANEIRO, K.C. Recomendação alternativa de cal cário para sol os altamente tamponados do extremo sul do Brasil. Ci. Rural, 29:651656, 1999.

AMADO, T.J.C. \& WILDNER, L.P. Adubação verde. In: SANTA CATARINA. Secretaria de Estado da Agricultura e Abastecimento. Manual de uso, manejo e conservação do solo e da água. 2.ed. Florianópolis, Empresa de Pesquisa Agropecuária e Difusão de Tecnologia de Santa Catarina, 1994. p.189-202.

BAYER, C. \& MIELNICZUK, J . Características químicas do solo afetadas por métodos de preparo e sistemas de cultura. R. Bras. Ci. Solo, 21:105-112, 1997.

BAYER, C.; MIELNICZUK, J. \& PAVINATO, A. Sistemas de manejo do solo e seus efeitos sobre o rendimento do milho. Ci. Rural, 28:23-28, 1998.

BLOOM, P.R.; MCBRIDE, M.B. \& WEAVER, R.M. Aluminum organic matter in acid soils, buffering and solution aluminum activity. Soil Sci. Soc. Am. J ., 43:488-493, 1979.

CAIRES, E.F. \& ROSOLEM, C.A. Calagem em genótipos de amendoim. R. Bras. Ci. Solo, 17:193-202, 1993.
CAIRES, E.F.; CHUEIRI, W.A.; MADRUGA, E.F. \& FIGUEIREDO, A. Alterações nas características químicas do solo e resposta da soja ao cal cário e gesso aplicados na superfície em sistema de cultivo sem preparo de solo. R. Bras. Ci. Solo, 22:27-34, 1998.

COMISSÃO DE FERTILIDADE DO SOLO - CFS-RS/SC. Recomendações de adubação e de calagem para os estados do Rio Grande do Sul e de Santa Catarina. 3.ed. Passo Fundo, SBCS-Núcleo Regional Sul, 1995, 224p.

DEPOLLI, H. \& CHADA, S.S. Adubação verde incorporada ou em cobertura na produçãode milho em solo de baixo potencial de produtividade. R. Bras. Ci. Solo, 13:287-293, 1989.

ERNANI, P.R. \& GIANELLO, C. Diminuição do alumínio trocável do solo pela incorporação de esterco de bovinos e camas de aviário. R. Bras. Ci. Solo, 7:161-165, 1983.

ERNANI, P.R. \& ALMEIDA, J.A. Comparação de métodos analíticos para avaliar a necessidade de calcário dos solos do estado de Santa Catarina. R. Bras. Ci. Solo, 10:143-150, 1986 .

ERNANI, P.R.; NASCIMENTO, J.A.L. \& OLIVEIRA, L.C. Increase of grain and green matter of corn by liming. R. Bras. Ci. Solo, 22:275-280, 1998.

ERNANI, P.R.; NASCIMENTO, J.A.L.; CAMPOS, M.L. \& CAMILLO, R.J. Influência da combinação de fósforo e calcário no rendimento de milho. R. Bras. Ci. Solo, 24:537$544,2000$.

HOYT, P.B. \& TURNER, R.C. Effects of organic materials added to very acid soils, on $\mathrm{pH}$, aluminum, exchangeable $\mathrm{NH}_{4}$, and crop yield. Soil Sci., 119:227-237, 1975.

LOURENÇO, A.J .; MATSUI,E.; DELISTOIANO, J .; BOIN, C. \& BORTOLETTO, O. Efeito de leguminosas tropicais na matéria orgânica do solo e na produtividade do sorgo. R. Bras. Ci. Solo, 17:263-268, 1993.

MIYAZAWA, M; PAVAN, M.A.\& CALEGARI,A. Efeito de material vegetal na acidez do solo. R. Bras. Ci. Solo, 17:411-416, 1993.

QUAGGIO, J.A.; SAKAI, M.; ISHIMURA, I.; SAES, L.A. \& BATAGLIA, O.C. Calagem para a rotação feijão-milho verde em sol o orgânico do vale da Ribeira del guapé(SP). R. Bras. Ci. Solo, 9:255-261, 1985.

SILVA, L.H.B.; MIRANDA, J .C.C. \& MIRANDA, L.N. Efeito da micorriza vesiculoarbuscular no crescimento de variedades detrigo sensível etolerante ao alumínio, em solo de cerrado. R. Bras. Ci. Solo, 18:407-414, 1994.

TESTA, V.M.; TEIXEIRA, L.A.J. \& MIELNICZUK, J. Características químicas de um podzólico vermel ho-escuro afetadas por sistemas de culturas. R. Bras. Ci. Solo, 16:107114, 1992.

VIDOR, C. \& FREIRE, J.R.J . Efeito da calagem e da adubação fosfatada sobre a fixação simbiótica do nitrogênio pela soja (Glycine max (L.) Merrill). Agr. Sulriog., 7:181-190, 1972.

WI LDNER, L.P. Adubação verde, cobertura erecuperação do solo em sistemas diversificados de produção. Chapecó, CPPP. 1990. 79p. (Relatório)

WUNSCHE,W.A.; DENARDIN,J .E.; MIELNICZUK,J .;SCOPEL, I.; SCHNEIDER, P. \& CASSOL, E.A. Projeto integrado de uso e conservação do solo - um esforço conjunto para a conservação do solo no Rio Grande do Sul. R. Trigo Soja, 51:20-25, 1980. 